\title{
Una serie ternaria verbalizadora:
}

\author{
temer-temor-atemorizar(se)
}

\author{
Ana Mosquera \\ Universidad de Santiago
}

En este trabajo me propongo reflexionar sobre las relaciones formales y semánticas existentes entre temer, temor y atemorizar(se). Estos tres términos léxicos se inscriben en el conjunto de series ternarias constituidas por un verbo base, un sustantivo deverbal y un verbo denominativo (esquema $\mathrm{V} \rightarrow \mathrm{N} \rightarrow \mathrm{V}$ ). En ellas se produce un doble proceso de derivación heterogénea mediante el cual se crean elementos pertenecientes a distinta categoría gramatical que sus respectivas bases.

No es esta la única tríada verbalizadora del español. Hay otras que repasaré de forma sucinta en el apartado 1. En el 2 examinaré más detenidamente la correlación derivativa que aquí interesa (la anteriormente reseñada, $\mathrm{V} \rightarrow \mathrm{N} \rightarrow \mathrm{V}$ ). Siguiendo a Pena (1993) consideraré los distintos subtipos que se pueden distinguir en ella en función de las relaciones formales y semánticas que se establecen entre sus integrantes. Con ello espero configurar el marco contextual adecuado para el estudio de temer, temor y atemorizar(se), que desarrollaré en el apartado 3.

\section{SERIES DERIVATIVAS TERNARIAS DE CREACIÓN VERBAL}

Pena (1993: 222-227) reseña cinco tipos de series ternarias que crean verbos mediante un doble proceso derivativo. El elemento inicial de todas ellas puede pertenecer a cualquiera de las tres categorías gramaticales básicas (verbo, adjetivo o sustantivo) y actúa como base para la creación de un sustantivo o adjetivo, sobre el que, a su vez, se forma 
un nuevo término léxico, en este caso de carácter verbal. En (1) se muestran las distintas posibilidades combinatorias:

(1)
a. $\mathrm{V} \rightarrow \mathrm{N} \rightarrow \mathrm{V}$ (temer - temor - atemorizar(se)).
b. $\mathrm{A} \rightarrow \mathrm{N} \rightarrow \mathrm{V}$ (capaz - capacidad - capacitar).
c. $\mathrm{V} \rightarrow \mathrm{A} \rightarrow \mathrm{V}$ (charlar - charlatán - charlatanear).
d. $\mathrm{N} \rightarrow \mathrm{A} \rightarrow \mathrm{V}$ (centro - central- centralizar).
e. $\mathrm{A} \rightarrow \mathrm{A} \rightarrow \mathrm{V}$ (bueno - mejor - mejorar)'.

Las series ternarias verbalizadoras tienen una productividad bastante restringida en español. La única que presenta cierta rentabilidad es la reseñada en (1d), $\mathrm{N} \rightarrow \mathrm{A} \rightarrow \mathrm{V}$, siempre y cuando el adjetivo sea de relación ${ }^{2}$. Adviértase además que esta serie es la única con una base denominal o, lo que es lo mismo, ninguna otra inicia el proceso derivativo mediante un sustantivo.

De ello se deduce que la productividad de las tríadas verbalizadoras está asociada al cumplimiento de determinados requisitos de índole categorial (es necesaria una base denominal) y semántica (el adjetivo en cuestión ha de ser de relación).

El tipo de serie que interesa en el presente trabajo no es este, sino el constituido por un verbo base, un sustantivo deverbal y un verbo denominativo (reseñado en (1a)). Los elementos que abren y cierran su ciclo derivativo pertenecen a la misma categoría gramatical (ambos son verbos), aunque la presencia de un elemento intermedio de carácter sustantivo propicia que el proceso de creación léxica sea heterogéneo y la verbalización se produzca mediante adyacencia mediata, no inmediata.

Este tipo de serie ternaria no es especialmente productivo y ello por

1 Esta serie está constituida por adjetivos en forma positiva, su correspondiente término en gradación comparativa (formado mediante flexión del sufijo -or y con carácter supletivo en aquellos casos en los que hay defección o separación de la palabra base) y un verbo derivado.

2 Desde un punto de vista semántico, los adjetivos pueden ser calificativos (si denotan cualidades y califican: bonito, pequeño, hábil) o de relación (si establecen relaciones y clasifican: americano, actual). Vid. Bosque (1989). 
un doble motivo. Uno, ya reseñado (la base derivada es deverbal y no denominal); el otro, la preferencia que el español muestra por la prefijación antes que por la sufijación en las correlaciones derivativas de creación verbal:

Resulta, pues, que el español no suele recurrir a la sufijación en la derivación verbal para formar series de derivación donde se repita la clase verbal en adyacencia cíclica inmediata (sufijación homogénea) o mediata (sufijación heterogénea). Acude más a la prefijación, pero tampoco tanto como en la prefijación nominal (Pena 1993: 227).

Uno de los rasgos más destacados de la serie (1a), $\mathrm{V} \rightarrow \mathrm{N} \rightarrow \mathrm{V}$, es el gran abanico de relaciones formales y semánticas que pueden mantener sus elementos integrantes. Esa heterogeneidad o falta de uniformidad puede sistematizarse mediante el establecimiento de ciertos subgrupos. Los más importantes se detallan en el próximo apartado.

\section{LA SERIE TERNARIA $\mathrm{V} \rightarrow \mathrm{N} \rightarrow \mathrm{V}$ : SUBTIPOS}

Suele considerarse condición indispensable para que dos o más elementos mantengan una relación derivativa que se relacionen formal y semánticamente. Esta afirmación debe matizarse, por lo menos en lo que respecta a la serie de (1a), pues las relaciones que se establecen entre sus integrantes son muy heterogéneas y variadas: pueden ser regulares pero también (y esto es lo más habitual) pueden presentar irregularidades en los ámbitos formal y/o semántico. Pena (1993: 226) detalla la situación, distinguiendo varios grupos:

2.1. El primero es muy numeroso ya que está conformado por más de la mitad de los casos. Se caracteriza por una carencia de tipo formal, cual es la ausencia del verbo base de la derivación. Por causas que no vienen al caso, este se pierde, pese a lo cual hay que tenerlo en cuenta, aunque sea de forma implícita, pues es la base a partir de la que se forman los restantes integrantes de la correlación derivativa.

Obviamente, un análisis de este tipo sólo puede realizarse desde una perspectiva etimológica o diacrónica, que ponga de manifiesto los an- 
tecedentes léxicos de cada término. Desde un punto de vista sincrónico, este tipo de carencias no se advierten (y, de hecho, tampoco resultan pertinentes). Ejemplos como los de (2) son ilustrativos:

(2) a. CENSE:RE $\rightarrow$ CENSURA $>\varnothing$, censura $\rightarrow$ censurar

b. LICE:RE $\rightarrow$ LICENTIA $>\varnothing$, licencia $\rightarrow$ licenciar

c. ALERE $\rightarrow$ ALIMENTUM $>\varnothing$, alimento $\rightarrow$ alimentar

Los verbos latinos base de estas series (CENSE:RE, ALERE y LICE:RE) no han tenido continuidad en español, aunque sí sus correspondientes sustantivos derivados (CENSURA > censura, ALIMENTUM > alimento y LICENTIA > licencia). A partir de ellos se crea un nuevo verbo de carácter denominativo (censurar, alimentar y licenciar) que palía en cierto modo la ausencia del originario pues su significado coincide con el del elemento perdido.

2.2. Los restantes casos (menos del $50 \%$ sobre el total de series ternarias $\mathrm{V} \rightarrow \mathrm{N} \rightarrow \mathrm{V}$ ), no presentan casillas vacías (tienen, pues, todos los huecos formales ocupados). Ello no garantiza que sus elementos mantengan relaciones regulares y previsibles en el plano formal y, mucho menos, en el semántico. De hecho, se advierte una notable heterogeneidad que es posible sistematizar mediante el establecimiento de diversos subtipos. Hay tres bastante definidos: el primero (2.2.1) está constituido por las series que carecen de vinculaciones directas en los planos formal y semántico; el segundo (2.2.2) lo conforman los casos en los que no hay continuidad semántica entre el verbo base y el sustantivo derivado de él; por último, el tercero (2.2.3) está configurado por aquellas series cuyos integrantes sí mantienen relaciones significativas, aunque estas sean de muy distinto tipo.

2.2.1. El caso más extremo lo constituyen series como las reproducidas en (3):

(3) a. Querer-cuestión-cuestionar.

b. Meter-misión-misionar.

c. Caber-captura-capturar.

En ellas, el verbo base de la derivación y el sustantivo derivado no se relacionan ni formal ni semánticamente. Este hecho resulta llamati- 
vo e incluso desconcertante pues, ¿cómo pueden entonces considerarse integrantes de una misma correlación si no mantienen relaciones en ninguno de los dos planos básicos? El análisis etimológico solventará estas dudas y mostrará que, efectivamente, hay cierta vinculación entre ellos, aunque esta sea indirecta y no se advierta desde una perspectiva estrictamente sincrónica.

Para ejemplificarlo, analizo la serie reseñada en (3a): querer-cuestión-cuestionar. En principio, parece difícil establecer una relación formal entre sus dos primeros términos, aunque las dificultades se resuelven al remitirse a sus antecedentes latinos: el verbo QUARERE (que evolucionará fonéticamente al español querer) y el sustantivo formado a partir de él, QUAESTIO-ONIS (que, a su vez, originará cuestión). Así pues, querer y cuestión no son términos léxicos que deriven fonéticamente uno del otro, pero es posible relacionarlos al mantener ambos algún tipo de vinculación con el étimo latino QUARERE: querer deriva directamente de él, en tanto que cuestión resulta de la evolución fonética de un sustantivo formado a partir de este verbo.

Desde un punto de vista semántico, querer y cuestión presentan notables diferencias significativas. Según indica Corominas en su Breve diccionario etimológico de la lengua castellana (en adelante, BDELC), el verbo latino QUARERE significaba "buscar", "inquirir", "pedir". Alguna de estas acepciones tuvo continuidad en el sustantivo derivado de él, QUAESTIO-ONIS, ("búsqueda", "problema", "interrogatorio"). La ligazón no se ha perdido ni siquiera en el término español cuestión ${ }^{3}$ ("pregunta que se hace o propone para averiguar la verdad de una cosa controvertiéndola"). Cuestionar continúa en esta línea (1. Controvertir un punto dudoso, proponiendo las razones, pruebas y fundamentos de una y otra parte. 2. Poner en duda lo afirmado por alguien).

Querer tiene actualmente en español dos acepciones básicas ("voluntad, deseo" y "amar"). Según indica el BDELC, la idea de voluntad

3 Utilizo el DRAE (1992) como fuente lexicográfica, tanto para este término como para los sucesivos. 
ya se encontraba esbozada en latín vulgar y de ahí se extendió a las lenguas romances, aunque actualmente sólo se conserva en gallego, portugués y español. La acepción de "amar" es más moderna y deriva de la anterior.

Así pues, querer-cuestión-cuestionar conforman una serie derivativa ternaria pese a que entre los dos primeros elementos léxicos se aprecia una ruptura semántica y formal. Esta última es más aparente que real, pues la adopción de un punto de vista diacrónico confirma que hay relación entre ambos términos. Precisamente, ello posibilita que se puedan integrar en la misma serie derivativa.

2.2.2. En las series ternarias $\mathrm{V} \rightarrow \mathrm{N} \rightarrow \mathrm{V}$ se puede distinguir un segundo subgrupo cuyos dos primeros elementos mantienen relaciones formales pero no semánticas. El sustantivo deverbal se desvía semánticamente del verbo base, arrastrando consigo al verbo denominativo que deriva de él. En estos casos se habla de opacidad o inmotivación semántica entre ambos elementos (verbo base y sustantivo deverbal) ya que no es posible establecer una relación significativa entre ellos:

(4) a. Conferir-conferencia-conferenciar.

b. Instruir-instrumento-instrumentar.

c. Sentir-sentencia-sentenciar.

Es fácil advertir las relaciones formales existentes entre los tres integrantes de cada serie: el sustantivo deverbal se crea tras añadir al verbo base los sufijos -ncia en (4a) y (4c) y -mento en (4b); el verbo denominativo se forma en los tres casos mediante la adición de la vocal temática verbalizadora $-a$ - a la base sustantiva.

Las relaciones semánticas son más complejas que las formales y, en consecuencia, también menos previsibles. Trataré de ejemplificarlas mediante el análisis de la serie (4b): instruir-instrumento-instrumentar. El DRAE (1992) recoge cuatro acepciones del verbo base de la correlación:

INSTRUIR: 1 tr. Enseñar, doctrinar. 2. Comunicar sistemáticamente ideas, conocimientos o doctrinas. 3. Dar a conocer a uno el estado de una cosa, informarle de ella, o comunicarle avisos o reglas de 
conducta. 4. Formalizar un proceso o expediente conforme a las reglas de derecho y prácticas recibidas.

El sustantivo instrumento tiene seis acepciones, aunque ninguna se relaciona con las presentadas por el verbo del que deriva formalmente. Las más importantes son las cuatro primeras (la quinta es figurada y la sexta se inscribe en el ámbito jurídico): 1. Conjunto de diversas piezas combinadas adecuadamente para que sirva con determinado objeto en el ejercicio de las artes y oficios. 2. Ingenio o máquina. 3. Aquello de que nos servimos para hacer una cosa. 4. Instrumento músico.

El verbo denominativo instrumentar tiene tres acepciones que siguen algunas de las líneas significativas del sustantivo instrumento. Un ejemplo, la primera definición lexicográfica remite al campo musical ("arreglar una composición musical para varios instrumentos") y, por tanto, se relaciona con la acepción 4 de instrumento, anteriormente reseñada.

Cuando entre el verbo base y el sustantivo derivado se producen discordancias formales y semánticas como las analizadas en $2.2 .1 \mathrm{y}$ 2.2.2, hay muchas posibilidades de que se cree un verbo denominativo (derivado del sustantivo deverbal). Es menos previsible que se produzca tal formación cuando los elementos iniciales del proceso derivativo mantienen relaciones formales y semánticas completamente regulares. Así ocurre en la serie crear, creación $n^{4}$. A partir de este sustantivo únicamente se podría crear el verbo *creacionar, pues el sufijo -ción sólo admite la adición del sufijo - $a$ - (este selecciona de forma exclusiva ese tipo de bases). Sin embargo, tal formación es agramatical porque la lengua posee ya un verbo (crear) con las mismas características semánticas y, evidentemente, sería innecesario y, sobre todo, antieconómico crear otro elemento léxico de similares prestaciones ${ }^{5}$.

4 Ejemplo tomado de Pena (1994-1995), p. 166.

5 Pese a todo, hay casos similares en los que la serie ternaria está completa y, consecuentemente, su tercer elemento constituye un innecesario neologismo: revisar-revisión-revisionar; conectar-conexión-conexionar o influir-influencia-influenciar. Sin duda, es una cuestión interesante que convendría analizar más exhaustivamente. 
2.2.3. Las series ternarias analizadas en los anteriores subapartados carecen de vinculaciones regulares en los planos formal y/o semántico (en ambos conjuntamente o sólo en el último de ellos). Las que se estudiarán a continuación mantienen relaciones en los dos ámbitos, aunque las existentes en el plano semántico son de naturaleza tan heterogénea y variada que se constituyen como criterio distintivo para el establecimiento de diversos subgrupos:

(I) Los integrantes de la serie derivativa mantienen una relación formal y semántica regular y previsible. Son casos como los reseñados en (5):

(5) a. Influir-influencia-influenciar.

b. Ornar-ornamento-ornamentar.

Hay continuidad entre los integrantes de cada serie ternaria, tanto desde un punto de vista formal como semántico. En el primero de estos ámbitos, se crea un nuevo elemento léxico mediante la adición de un sufijo derivativo a la correspondiente base, en una operación completamente regular. Desde un punto de vista semántico, tampoco se detectan anomalías, pues se puede establecer correspondencia entre las acepciones de los diferentes términos.

En (5a) el sustantivo deverbal se forma mediante la adición del sufijo -ncia al tema verbal, mientras que el verbo denominativo se crea a través de la adición del sufijo verbalizador $-a$-. Desde un punto de vista semántico, influir es "producir unas cosas sobre otras ciertos efectos". El sustantivo deverbal influencia mantiene una clara correspondencia con su base, pues presenta como acepción básica "acción y efecto de influir" (tiene otros dos valores denotativos aunque son figurados). Influenciar, por su parte, es considerado por el DRAE sinónimo de influir.

(II) Un segundo tipo de relación semántica se establece en aquellas series derivativas cuyo sustantivo deverbal selecciona únicamente algunas de las acepciones de su verbo base, las cuales transmite al verbo que deriva de él. Se inscriben en este grupo, series como las de (6):

(6) a. Referir-relato-relatar.

b. Saber-sabor-saborear.

c. Diferir-diferencia-diferenciar. 
Entre las diversas acepciones que el DRAE recoge del verbo referir (serie 6a), únicamente una de ellas tiene continuidad en el sustantivo deverbal relato. A saber, "dar a conocer, de palabra o por escrito, un hecho verdadero o ficticio". Su influjo se percibe en los dos valores denotativos atribuidos a relato, muy especialmente en el primero de ellos (1. Conocimiento que se da, generalmente detallado, de un hecho. 2. Narración, cuento).

El verbo denominativo relatar sigue esa línea (1. Referir o dar a conocer un hecho. 2. Hacer relación de un proceso o pleito. 3. Intr. Refunfuñar o protestar, gruñendo por algo). Es evidente que las acepciones léxicas de este término están condicionadas por aquellas que presenta el elemento del que deriva: los valores denotativos que este selecciona de su verbo base son los únicos que, a su vez, puede transmitir al verbo denominativo que se forma a partir de él.

III) Todavía se puede distinguir un tercer tipo de relación semántica entre los términos que integran las series ternarias $\mathrm{V} \rightarrow \mathrm{N} \rightarrow \mathrm{V}$. Se trata de una vinculación significativa de tipo gramatical, no léxico, del que es buen exponente temer-temor-atemorizar(se). Su análisis, objeto central del presente estudio, se detalla en el siguiente apartado.

\section{TEMER-TEMOR-ATEMORIZAR(SE)}

\subsection{ANÁLISIS FORMAL}

La relación formal existente entre los integrantes de esta tríada es completamente regular. Cada término derivado se forma mediante un proceso morfológico que implica una o varias operaciones de afijación (sufijación en el caso de temor y parasíntesis en el de atemorizar). Todas ellas se desarrollan de forma regular y no propician modificaciones inesperadas respecto a la base de la derivación.

Analizo esta serie ternaria desde un punto de vista etimológico y contrasto su estudio con el de otras correlaciones derivativas también pertenecientes al campo semántico del 'miedo', ya que me interesa destacar la singularidad de temer-temor-atemorizar(se) respecto a ellas. 
En latín, la mayor parte de verbos en -e:- denotaban estados y actuaban muy frecuentemente como base para la formación de nuevos términos léxicos, tanto de carácter nominal (sustantivos en -or y adjetivos en -idus), como verbal (verbos incoativos en -scere y causativos en -a:-). Estas opciones no siempre se hacían efectivas: las carencias eran más frecuentes en el ámbito verbal (a partir de TIME:RE se creó una forma ingresiva, TIME:SCERE, pero no una causativa) que en el nominal, donde se solían explotar todas las posibilidades. (7) es un buen ejemplo de ello: muestra series derivativas pertenecientes al campo semántico del 'miedo', constituidas por verbos en -e:re y sus correspondientes derivados nominales:

(7)
Verbo en -e-:
TIME:RE HORRE:RE PAVE:RE TERRE:RE
Adjetivo en -idus: TIMIDUS HORRIDUS PAVIDUS TERRIDUS
Sustantivo en -or: TIMOR HORROR PAVOR TERROR

Me centro en el binomio verbo-sustantivo deverbal y, más concretamente, en la pareja objeto de estudio en el presente trabajo, TIME:RE-TIMOR. El procedimiento empleado para la creación del sustantivo se refleja en (8): adición del sufijo -or a la raíz verbal TIM- (resultante de eliminar de la forma verbal plena, TIME:RE, la vocal temática -E:- y el sufijo flexivo -RE):

$$
[\mathrm{TIM}-(\mathrm{E}-\mathrm{RE})]_{\mathrm{V}}+-\mathrm{OR} \rightarrow[\mathrm{TIMOR}]_{\mathrm{N}}
$$

El español heredó los dos términos léxicos implicados en esta operación derivativa. Las variantes experimentadas por los mismos son mínimas y, en cualquier caso, resultan de la evolución fonética esperada: TIME:RE > temer, TIMOR > temor.

La continuidad de esta pareja verbo-nominal constituye una excepción y, por tanto, no ejemplifica una tendencia habitual. La mayor parte de verbos de estado -e:- no se conservaron en el paso del latín al castellano. De los ejemplificados en (7), el único que tuvo continuidad fue TIME:RE; los restantes se perdieron y, por tanto, carecen de continuadores directos en español. Su ausencia dejaba un tanto aislados a los correspondientes sustantivos y generaba una importante carencia que la lengua no tardó en subsanar: tomando como base los sustantivos 
en -or y añadiéndoles el sufijo -iz-a- (de valor generalmente causativo), creó nuevos verbos que paliaron el desequilibrio anterior.

La continuidad de TIME:RE (> temer) en español, hacía innecesaria la creación de un nuevo elemento verbal. Sin embargo, siguiendo las pautas establecidas en los restantes casos, temor se constituyó en base para la formación de atemorizar. Sin duda, en ello desempeñó un importante papel la analogía con terror $\rightarrow$ aterrorizar y horror $\rightarrow$ horrorizar, aunque tampoco debe olvidarse la incidencia que pudo tener el valor causativo presente en la nueva forma verbal hispánica y ausente en la derivada latina.

Atemorizar se creó mediante la adición de los afijos $a$ - e -iz-a(r) a la base nominal temor. El proceso derivativo es completamente regular pues, tal y como se aprecia en (9), los constituyentes se adjuntan sin que se registre ninguna anomalía fonológica en ellos. No ocurre siempre así. En verbos similares, también formados mediante la adición del sufijo-iz- $a$ - a una base nominal, sí se producen modificaciones que se explican mediante las llamadas "reglas de reajuste". Es el caso de analizar, que deriva del sustantivo análisis: como puede advertirse en (10), el sufijo final de esta base nominal (-sis) se trunca o pierde tras la adición del afijo verbalizador -iz-a-:

(9) $a-+[\text { temor }]_{N}+-i z-a(r) \rightarrow[\text { atemorizar }]_{\mathrm{V}}$.

(10) $[\text { análisis }]_{\mathrm{N}}+-i z-a(r)-\rightarrow[\text { analizar }]_{V}$.

El proceso derivativo mediante el cual se forma atemorizar se denomina parasíntesis y consiste en la adición de un prefijo y un sufijo a una determinada base. Su interpretación plantea problemas y, de hecho, ha suscitado un importante debate en el que no voy a entrar. La discusión se centra básicamente en si la doble afijación es simultánea o sucesiva. De optarse por esta última alternativa, hay dos posibilidades: que el proceso de sufijación sea previo al de prefijación o viceversa, que este anteceda a aquel.

El verbo denominativo creado (atemorizar) presenta rasgos distintos del derivado latino (temer), lo que posibilita que ambos sean compatibles en un mismo estadio lingüístico. De no ser así, su copresencia 
sería poco factible, fundamentalmente por motivos de economía lingüística: al presentar similares valores semánticos, se solaparían creando una innecesaria redundancia (recuérdese lo dicho en (2.2.2) a propósito de crear-creación-*creacionar).

En (11) se refleja de forma esquemática la evolución experimentada por las principales parejas verbo-nominales del campo semántico del 'miedo' en el paso del latín al castellano:

(11) a. TERRE:RE $\rightarrow$ TERROR $>\varnothing$, terror $\rightarrow$ aterrorizar

b. HORRE:RE $\rightarrow$ HORROR $>\varnothing$, horror $\rightarrow$ horrorizar

c. TIME:RE $\rightarrow$ TIMOR $>$ temer, temor $\rightarrow$ atemorizar

La serie de temor es más completa que la de sustantivos similares como horror o terror. No ha perdido ninguno de los elementos que originariamente la conformaban (los derivados de los étimos latinos TIME:RE y TIMOR, verbo base y sustantivo deverbal, respectivamente) e incluso la ha ampliado con la creación de un nuevo verbo (atemori$z a r$ ). En cambio, las restantes series no tienen sus huecos formales totalmente cubiertos, pues carecen del verbo base (el existente en latín no ha tenido continuidad). Aunque tratan de compensar tal ausencia con un verbo de creación hispánica, que forman a partir del sustantivo deverbal (horror $\rightarrow$ horrorizar y terror $\rightarrow$ aterrorizar), con él no consiguen ocupar el hueco dejado por el iniciador de la correlación derivativa, ya que las características de una y otra forma verbal son distintas $\mathrm{y}$, en consecuencia, no pueden sustituirse mutuamente.

La serie ternaria temer-temor-atemorizar(se) está, por tanto, compuesta por dos términos heredados del latín (el verbo base y el sustantivo deverbal) y un tercero de creación hispánica (el verbo denominativo). Este hecho es específicamente característico de esta correlación derivativa y permite singularizarla frente a otras con las que comparte un mismo ámbito significativo (está constituida por tres elementos léxicos cuando las restantes únicamente tienen dos y, como consecuencia de ello, implica mayores valores significativos).

Es interesante reseñar que el español heredó los términos léxicos latinos TIME:RE y TIMOR ( $>$ temer, temor) pero no la pauta derivativa que 
los relaciona (adición del sufijo -or a la base verbal). Pena (1980) establece que esta ya se perdió en la propia lengua latina, donde sólo estuvo vigente hasta la época ciceroniana sin que hasta ese momento su contribución hubiese sido excesivamente importante ni en términos cuantitativos ni cualitativos. Se trata, por tanto, de un mecanismo derivativo inexistente en español y no de un procedimiento nominalizador actualmente improductivo después de haber sido rentable en otros periodos lingüísticos.

\subsection{ANÁlISIS SEMÁNTICO}

Al igual que en los anteriores casos, en el análisis semántico de esta serie ternaria trataré de determinar si hay o no correspondencia entre las acepciones de la palabra base y las de los términos derivados. Para ello, utilizo diversas fuentes lexicográficas: además del DRAE que he empleado a lo largo del estudio, manejo el Diccionario de uso del español de María Moliner (DUE) y Clave. Diccionario de uso del español actual (DCL).

3.2.1. El cotejo de las definiciones que todos ellos proponen para temer me permite deducir que este verbo tiene tres significados básicos: 1. Tener miedo de alguien o algo (una persona, un animal o una cosa). 2. Recelar, sospechar (pensar que ocurre, va a ocurrir o puede ocurrir algo malo). 3. Sentir temor por alguien o algo.

Llego a esta conclusión tras analizar las propuestas planteadas por cada uno de los tres diccionarios consultados, ninguna de las cuales coincide, por cierto. El DRAE recoge cuatro acepciones: son las tres reseñadas, con la división en dos distintas de la segunda de ellas (distingue entre "sospechar, creer": temo que sea más antiguo de lo que cree, $\mathrm{y}$ "recelar un daño en virtud de un fundamento antecedente": temo que vendrán mayores males). El DuE considera únicamente dos significados (no reconoce la acepción "sentir temor o preocupación", que está ligada al esquema sintáctico SUJ-PRED-CPREP: temo por mis hijos, temo por tu salud porque fumas demasiado). Por su parte, el DCL mantiene una postura intermedia al recoger las tres acepciones anteriormente consignadas. 
En consecuencia, dos son los puntos conflictivos en torno a los que no hay acuerdo: por un lado, ¿"sospechar, creer" y "recelar un daño" son acepciones distintas, tal y como propone el DRAE, o se trata de un mismo valor significativo?; por otro lado, $i$ "sentir temor por alguien o algo" debe considerarse una acepción independiente?

Ya he manifestado anteriormente mi opinión al proponer el tratamiento lexicográfico que consideraba más adecuado para este verbo. Respecto a la primera de las cuestiones planteadas, entiendo que hay una única acepción y no dos distintas, y en lo relativo a la segunda, considero que temer por codifica un valor significativo independiente. Los criterios en los que me baso son distintos en uno y otro caso. En el segundo, tienen carácter básicamente formal y remiten a la idea de que las estructuras sintácticas mediante las cuales se codifica un verbo constituyen un factor sumamente útil para determinar sus acepciones. En temer, se registran dos distintas: SUJ-PRED-CPREP y SUJ-PREDCDIR, con subdivisión de esta última según el CDIR sea frástico (temo una recaída, temo a las tormentas) o clausular (temo que les haya pasado algo). Por tanto, atendiendo a este criterio de tipo formal, temer por codifica una acepción diferente e individualizada de este verbo (la reseñada anteriormente como 3), planteamiento recogido en sus propuestas por el DRAE y DCL.

Más difícil resulta pronunciarse respecto a la distinción que el DRAE realiza entre "sospechar, creer" por un lado, y "recelar de un daño futuro" por otro. En este caso, a diferencia del anterior, no hay criterios formales a los que remitirse para optar por una u otra alternativa (ambas se codifican mediante la estructura sintáctica SUJ-PRED-CDIR [cláusula con que]). Los criterios semánticos en los que se intenta basar esta propuesta son menos sólidos y resultan difíciles de precisar. El propio DRAE acusa la inconsistencia de su planteamiento: las secuencias con las que trata de ejemplificar cada una de estas supuestas acepciones son poco clarificadoras y no evidencian esa pretendida distinción semántica. Por todo ello, creo que es más conveniente obviarla, tal y como hacen el DuE y DCL.

3.2.2. El tratamiento lexicográfico de temor también suscita ciertas 
discrepancias, aunque de menor grado que las revisadas a propósito de temer. El DRAE reseña cuatro acepciones de este sustantivo: se muestra coherente y así, si distinguía en el verbo temer las acepciones de "sospechar" y "recelar", en el sustantivo derivado temor sigue una línea similar. De este modo diferencia entre "presunción o sospecha" por un lado (acepción 2) y "recelo de un daño futuro" (acepción 3), por otro. Los otros dos significados considerados son "pasión del ánimo, que hace huir o rehusar las cosas que se consideran dañosas, arriesgadas o peligrosas" y un sentido muy específico, propio de la germanía (la jerga o manera de hablar específica de los ladrones y rufianes). En ella, temor significa "cárcel de presos".

DuE y DCL únicamente recogen dos acepciones de este sustantivo (sentimiento de miedo hacia alguien o algo; recelo o sospecha). Este diferente tratamiento lexicográfico se explica fácilmente teniendo en cuenta que el diccionario académico a) considera distintas dos acepciones que los otros diccionarios engloban en una sola y b) reseña una acepción muy restringida, propia de una jerga concreta, cuyo uso es sumamente limitado. Esta circunstancia determina que las otras dos fuentes lexicográficas no la consignen, pues tanto DUE como DCL son diccionarios de uso del español y esta acepción de temor no se encuentra, evidentemente, entre las más empleadas.

El análisis lexicográfico comparativo de temer y temor pone de manifiesto una notable correspondencia entre las acepciones significativas de ambos términos. Dos de los tres significados del verbo base tienen continuidad en el sustantivo derivado (tener miedo y sospechar, recelar). Un factor importante en ello es, sin duda, la aportación de tipo gramatical (no léxico) que el sufijo nominalizador -or realiza al proceso derivativo (informa que el elemento en el que se incluye es un sustantivo deverbal de carácter abstracto).

3.2.3. Como suele ser habitual en las series ternarias derivativas, el elemento que ocupa la última posición en la correlación presenta una semántica más restringida y limitada que los dos precedentes. El caso de temer-temor-atemorizar(se) no constituye una excepción y así, el verbo denominativo tiene un significado muy específico. Esto facilita 
su tratamiento lexicográfico y posibilita que los tres diccionarios consultados coincidan al otorgarle valor causativo a este término, parafraseable por "causar miedo o temor".

No se advierte, sin embargo, idéntico consenso respecto a otro aspecto fundamental de atemorizar(se): su "alternancia causativa" o codificación mediante dos esquemas sintáctico-argumentales, el biactancial transitivo con valor propiamente causativo (la tormenta atemorizó a los niños) y el monoactancial intransitivo, asociado a la construcción pronominal o en voz media y cuyo significado es incoativo (los niños se atemorizaron). Ambos valores constituyen una única acepción, en la que el significado transitivo es el básico y el incoativo el secundario (constituye, pues, una subacepción de aquel y no un valor léxico independiente).

Los tres diccionarios consultados analizan esta importante cuestión de modo distinto: el DRAE ni la considera (se limita a reseñar el valor causativo del verbo, sin hacer mayores precisiones); el DCL no la menciona de forma explícita, aunque parece reconocerla implícitamente en la ejemplificación que propone (no atemorices a tu hermano pequeño hablándole de fantasmas; se atemorizó con los gritos); el DuE propone el tratamiento aquí postulado (un significado causativo principal con una subacepción de carácter incoativo), aunque también reconoce un segundo valor secundario, cuya existencia me parece discutible ("intimidar", "quitar a alguien el valor para hablar, moverse o actuar": el maestro atemoriza a los niños con sus gritos).

La comparación lexicográfica de temor y atemorizar(se) pone de manifiesto que la relación semántica establecida entre estos dos términos léxicos es distinta de las analizadas en el apartado anterior a propósito de otras series derivativas. De las dos acepciones de temor (sentimiento de miedo y sospecha o recelo), la única que tiene continuidad en atemorizar(se) es la primera de ellas aunque, por sí sola, no explica el significado de este verbo denominativo. El valor causativo que este presenta resulta de combinar los significados aportados por el sustantivo y el sufijo verbalizador $-i z-a(r)$ o, para ser más exactos, el esquema parasintético [a---izar]. 
Respecto a esta cuestión, se plantean diversos interrogantes: ¿tiene que haber correspondencia cuantitativa y cualitativa entre significante y significado?, esto es, ¿cada constituyente debe tener un significado determinado y preciso? En el caso de atemorizar(se) parece difícil mantener tal premisa pues resulta complicado (por no decir imposible) sistematizar el significado del prefijo $a-^{6}$.

La alternativa más factible es considerar que el esquema [a---izar] aporta de modo conjunto la significación causativa. En contra de tal hipótesis puede argumentarse que el sufijo $-i z-a$-suele tener, por sí solo, valor causativo (así lo demuestran verbos como paralizar, sistematizar $\mathrm{u}$ horrorizar, entre otros muchos).

3.2.4. Tras lo dicho, se pueden establecer diversas conclusiones respecto a la relación semántica existente entre los términos integrantes de la tríada temer-temor-atemorizar(se). Se advierte continuidad significativa entre ellos, aunque también una progresiva reducción en su número de acepciones: dos de las tres que presenta temer se mantienen en su sustantivo derivado temor, aunque con las lógicas variaciones resultantes del cambio de categoría gramatical que se produce en el proceso de derivación morfológica. Atemorizar(se) presenta, por su parte, una única acepción que se explica, aunque sólo sea de modo parcial, a través de uno de los dos significados de temor. A ella hay que añadir los valores aportados por los afijos que intervienen en el proceso derivativo mediante el cual se crea este verbo denominativo; el carácter de los mismos es esencialmente gramatical (así hay que calificar la noción de causatividad, un valor que adquiere un significado concreto y preciso al adicionarse a los restantes elementos que intervienen en el proceso derivativo).

Temer-temor-atemorizar(se) no constituye un caso único y aislado. La relación semántica de tipo gramatical que mantienen sus elementos integrantes también se aprecia en otras series ternarias (amor-amar-

6 Este hecho implica una cuestión más general y compleja que aquí no puedo tratar, cual es la semántica de los prefijos. 
enamorar(se), oler-olor-olorizar o distar-distancia-distanciar). Correlaciones derivativas parcialmente semejantes, que no idénticas, son fisgar-fisgón-fisgonear y tragar-tragón-tragonear: ambas están conformadas por un verbo base, un sustantivo en -ón, - $a$ y un verbo denominativo que expresa acción habitual, típica de los nombres de los que deriva (vid. Pena 1993: 226-227).

\section{CONCLUSIÓN}

En este trabajo he analizado la serie ternaria temer-temor-atemorizar(se) desde una doble perspectiva semántica y formal. Para obtener una visión más completa de la misma, he considerado el contexto en el que se integra: el de las series $\mathrm{V} \rightarrow \mathrm{N} \rightarrow \mathrm{V}$. Para ello, he partido de la panorámica esbozada por Pena (1993), en la que se establecen ciertos rasgos generales de este tipo de correlación derivativa y se consideran diversos subgrupos atendiendo a los rasgos formales y semánticos de sus integrantes. Su propuesta podría resumirse esquemáticamente en los siguientes términos:

Series ternarias $V \rightarrow S \rightarrow V$ (verbo base - sustantivo deverbal - verbo denominativo):

$+50 \%$ casos: series formalmente incompletas (ausencia del verbo base);

+ $25 \%$ casos: opacidad o inmotivación semántica del sustantivo deverbal respecto al verbo base;

- 25\% casos: relación semántica entre los elementos de la serie ternaria a) regular o previsible, b) restrictiva (el sustantivo deverbal selecciona acepciones de verbo base) o c) gramatical.

Las clasificaciones o divisiones no son siempre excluyentes. Así, los integrantes de una serie ternaria pueden mantener relaciones semánticas de carácter restrictivo o selectivo y, al mismo tiempo, gramatical. Es el caso de correlaciones como diferir-diferencia-diferenciar o crecer-creciente-acrecentar y, en menor grado, de la serie aquí analizada, temer-temor-atemorizar(se). 
La situación admite otras perspectivas de análisis:

I. En principio, lo esperable sería que los integrantes de las series ternarias mantuviesen una relación formal y semántica más o menos regular.

II. Sin embargo, esta no es la situación prototípica o paradigmática, entendiendo por tal la más habitual. De hecho, son mucho más frecuentes las que podríamos denominar "desviaciones" respecto a lo esperado, que pueden tener carácter formal o semántico. Las primeras se concretan en la ausencia del verbo base de la serie derivativa $[(\varnothing \rightarrow)$ $\mathrm{S} \rightarrow \mathrm{V}$ ] o en la falta de relación formal entre el verbo base y el sustantivo denominal. Las desviaciones semánticas consisten en la pérdida de relación semántica entre el verbo base y el sustantivo deverbal (y, consecuentemente el verbo denominativo), en la restricción de acepciones del sustantivo deverbal respecto al verbo base o en el establecimiento de una relación de tipo gramatical.

El panorama esbozado constituye el marco en el que se contextualiza el análisis de temer-temor-atemorizar(se). Los integrantes de esta serie ternaria mantienen unas relaciones formales y semánticas reconocibles y analizables como tales. Las primeras son totalmente regulares (propician los cambios esperados en los procesos derivativos) en tanto que las segundas tienen un carácter esencialmente gramatical. Este se establece a partir de la aportación de los sufijos implicados en los procedimientos de derivación: proporcionan información de carácter morfológico en torno a la categoría gramatical del elemento en el que se incluyen y aportan rasgos significativos, en ningún caso de carácter léxico (-or es un sufijo nominalizador abstracto, en tanto que -iz-a- es verbalizador y tiene valor esencialmente causativo).

\section{BIBLIOGRAFÍA}

\section{A) Diccionarios}

BDLEC: COROMINAS, Joan (1973): Breve diccionario etimológico de la lengua castellana, Madrid, Gredos, $3^{\text {a }}$ edición [1961]. 
DCl: Maldonado, Concepción (dir.) (1997): Diccionario de uso del español actual, Madrid, S.M.

Drae: Real ACAdEMta EsPañola (1992): Diccionario de la lengua española, Madrid, Espasa Calpe, $21^{\mathrm{a}}$ edición.

DUE: Moliner, María (1998): Diccionario de uso del español, Madrid, Gredos, $2^{a}$ edición [1966-1967].

B) Estudios

BosQUE, Ignacio (1989): Las categorías gramaticales, Madrid, Síntesis.

LÁZARO CARRETER, Fernando (1971): "Transformaciones nominales y diccionario", Revista de la Sociedad Española de Lingüística 1/2, pp. 371-379.

PENA, Jesús (1980): La derivación en español: verbos derivados y sustantivos verbales, Santiago de Compostela, Universidad de Santiago de Compostela.

- (1993): "La formación de verbos en español: la sufijación verbal", en Soledad Varela (ed.), La formación de palabras en español: la sufijación verbal, Madrid, Taurus, pp. 217-281 y 389-400.

— (1994-1995): "Formación de palabras, gramática y diccionario", Revista de Lexicografia, I, pp. 163-181. 